\title{
Improvisation as Contingent Encounter, Or: The Song of My Toothbrush
}

\section{Dan DiPiero}

As readers of this journal will know, critical improvisation scholars have almost uniformly declined to define improvisation as such in favor of highlighting the work that it can do, a stance I take as (perhaps ironically) reflective of a definitional understanding of improvisation as an active process, rather than a static relation. In this essay, I will hazard a definition of improvisation not in order to settle any debates, but in order to provoke and re-orient exactly the question of what improvisation can do. My argument here is that-for all its multiple valencesimprovisation as a term can be defined through its relationship with contingency, and consequently that thinking improvisation through a contingentist framework can raise productive questions about what it means to improvise in a given context.

At first, the idea is obvious: clearly, improvisers are concerned with contingency, since unpredictability is what ostensibly distinguishes improvisation from other activities. However, pushing the idea further, it is also clear that improvisers do not simply pursue maximum unpredictability, as if the success of an improvisation is negatively correlated with its degree of foreseeability. Thus, improvisation must have a particular kind of relationship with contingency. The first part of this essay will explore how we might think of this relationship, or what it might mean to bring contingency to bear on questions of improvisation. Subsequently, I briefly compare two musical examples through a contingentist lens: Eric Dolphy's "Out to Lunch," and a 2015 track from Norwegian free improvisers, Mr. K. Finally, I reflect on what contingency reveals about thinking improvisation, whether in music or social life.

\section{Brushing}

I want to begin by taking seriously two interrelated claims. The first is an offhand comment that Vinny Golia made while teaching, and which has stuck with me for years. Without much explication, he claimed that "You're improvising when you brush your teeth," a statement that explicitly locates improvisation in a routine, everyday activity. This paper is not the place to catalogue the myriad understandings of "improvisation" that have emerged in the recent wave of scholarship;" suffice it to say that Golia's statement would seem to cut against many of these understandings, particularly those invested in the composition/improvisation binary, or those which emphasize the "subversive" elements in improvisation. ${ }^{2}$ While improvisation has been expanded and extensively nuanced in much current literature, it is also still common to find associations between improvisation and a certain set of generative, progressive terms. If, for example, improvisation involves listening to others, doing something unpredictable, or undermining established orthodoxies, how can Golia's statement regarding one of the most routine and banal behaviors of everyday life be taken seriously? Does the routine not represent improvisation's opposite?

The second claim bears on the first, and was made by Vijay lyer in a well-known conversation with DJ Spooky about improvisation and digital culture. In this roundtable, lyer asserted that "Everyday life is improvised to the extent that it becomes invisible" (Spooky and lyer 233). For lyer, then, the fact that teeth-brushing seems routine, predictable, and banal would be less because of some quality inherent to the act itself and more a reflection of the narratives that we ascribe to such acts. In other words, the improvisation of oral hygiene is invisible. 
Critical Studies in Improvisation / Études critiques en improvisation, Vol. 12, No. 2

What lyer is touching on in his comment, I believe, has little to do with improvisation's standard tropes, but rather with a more expanded understanding that I characterize first as a contingent encounter. I use this definition as an experiment, rather than a judgment, ${ }^{3}$ to see what emerges from pushing the claim as far as it can go. ${ }^{4}$ Viewing improvisation through the lens of contingency, I argue, highlights several of improvisation's important characteristics while also leaving behind the set of binary assumptions that continues to dog the term, and which renders quotidian improvisations invisible. Additionally, I argue that defining improvisation in this way can offer a strategy for avoiding some of the epistemological risks involved in declining to define improvisation. Below, I will highlight some of these characteristics before offering a comparison of two musical examples.

\section{Contingency}

Contingency-like improvisation-is a word that has been mobilized towards all kinds of theoretical purposes. It has developed meanings that refer to both: A) particular (what Aristotle calls "accidental") qualities that "could have been otherwise" 5 (implying that they are, that they exist, that the question is closed) and also B) those outcomes that have yet to be determined (as in contingent on, so that the question is open). Within these two categories, there are of course myriad terms used to describe contingent musical practices, each of which in some way bear on questions of causality. These include: chance, indeterminacy, complexity, emergence, event, and improvisation itself. ${ }^{6}$ Each of these terms references a specific kind of causality, but each of them can also be described as contingent. Contingency thus functions as something of an umbrella term for events that either were or will be decided according to some non-linear causality, a term that is cleaved in half depending on where in a temporal process one chooses to look.

Before the event, the outcome is contingent as in not-yet-known; after the event, the result is contingent as in could-have-been-otherwise. What appears at first blush a frustrating theoretical ambiguity actually points to a useful insight: at any given time in any given process, there is a particular constellation of openings and closures, of possibilities and impossibilities, that constitute a contingent situation. Thus, the contingent does not reference either the open or the already decided but both at once, and always. Before the event, the constellation looks one way, and after the event it looks another way (plus all points in between). What is the same in any case is that each closure engenders a new opening, and every opening guarantees a future closure. Closures and openings are immanent to one another, each a part of what makes a situation as such. Thus, the notion of contingency that I aim to outline here moves beyond its traditional opposition to "necessity" and instead incorporates closures and openings together. The fact that contingency refers to both that which is determined (but could have been differently so) and that which will be determined (and is yet unknown) is an insight as much as it is a paradox; both of these moments are a part of what constitutes a contingent formation.

\section{Constellation}

This first insight is particularly useful in bypassing the binaries that often accompany discussions of improvisation. Even where improvisatory acts are described on a kind of sliding scale-for example, from all the way closed (as in classical music) to all the way open (as in free jazz) - the question is always posed between the poles of freedom and restriction. ${ }^{7}$ While the composition/improvisation binary has been more thoroughly undermined of late, ${ }^{8}$ it is still difficult to conceive of improvisation and its significance without a series of associated binaries, namely: freedom/constraint, predictable/unforeseen, habitual/extraordinary, planned/unplanned, process/product, hegemonic/radical, and what I am calling here "open/closed." 
I do not claim that these oppositions are not at least somewhat in play in a given improvisation. I do claim, however, that theorizations of improvisation and other contingent artworks tend to follow from the moment in the process that is privileged at a given point, while neglecting the moments in the creative process that seem less relevant. Consequently, improvisation, considered in the 'during' moment of creation, has traditionally been about openness, while contingent painting (for instance), considered in the 'after' of the process, becomes about closedness (i.e., the result). In other words, the way openness and closedness figure into a situation again has to do with our narratives or particular viewpoints.

Because of this emphasis on the openness of improvised music, thinking improvisation as "unforeseen" or "unplanned" activity is a persistent characterization that has overdetermined theorizations of improvisation. Alternatively, the first consequence of thinking improvisation according to contingency is that the open/closed binary collapses, complicating readings that rely on associated political notions like freedom/restraint, or vertical/horizontal. Rather than viewing improvisation as something that is more or less present, more or less open on a sliding scale, contingency invites us to consider every improvisation as non-trivially different-a constellation of openings and closures both, in a singular arrangement.

\section{Interdependence}

The second characteristic that contingency points to is the fundamental state of interdependence that constitutes all improvisations. Several scholars have written on the interdependence of improvised music performance, and from a variety of perspectives. Nick Nesbitt, for instance, argues from a Deleuzian vantage that musical production is the result not of a "metaphysics of human productivity" but of networked associations of "asubjective sounding machines," as in an "instrument-club-musician-head-solo-influences-practice-time-mood assemblage" (Nesbitt 159-160). From an arguably related perspective, David Borgo and Marcel Cobussen have each written about improvisation as an emergent phenomenon, noting both its embodied and situated qualities (on which lyer has also written extensively, coming from a neurocognitive viewpoint) as well as its contingent patterns of actualization. ${ }^{9}$ Equally, many musicians have attested to the veracity of such assessments. For example, Pauline Oliveros spoke often of the transformative influence of the environment in the Dan Harpole cistern on both her musical performances and her overall philosophico-aesthetic practice. ${ }^{10}$ Meanwhile, every musician knows the difference that even an ostensibly identical instrument can make on one's performance, the difference between "a bass" and "my bass." What each perspective has in common is the interactive relationship between subjects, objects, and multiple environments. ${ }^{11}$

Thinking contingency takes the premise of interdependence to its furthest extreme: in this view, it is not that discrete, isolated entities connect themselves to form something greater, but rather that the distance between the musician as subject and the instrument as object is not clearly defined. Whereas subject-oriented analyses based in what Erin Manning calls the "volitionintentionality-agency triad" (Manning) see these factors as subordinated to the acting subject, the notion of contingency emphasizes the fact that the improvisation, in a deep way, dependsthat is, it is not made up of component parts that get connected together, because the component parts do not pre-exist as isolable entities; they are already contaminated with one another as they are expressed in the event. ${ }^{12}$ Indeed, this insight is also one that arises from improvisation itself. As Tracy McMullen writes:

Improvisation privileges listening and responding and therefore highlights intersubjectivity - the ways our actions and sense of self are constantly constructed 
through interaction with our environment. Improvisation is a practice where actions and responses are not enforced, but also do not arise completely independently. Much like daily life, musical improvisation is a complex system of interaction, negotiation, and coarising.

The factors present in a given improvisation account for the singular arrangement of possibilities and impossibilities even as they give rise to one another. This interdependence and interaction produce the unique formation of a contingent event. From this perspective, understanding what it means to improvise in a given situation would involve tracing the singularities present in that situation, and the constellation of likelihoods and tendencies that these specific factors engender. It is the arrangement of these participants as they emerge in performance that determines the unique color, shade, or arrangement of potentialities in play.

\section{Affect}

Third, and as an important supplement to everything else: the "arrangement" of "participants" and the "determination" of their "potentialities" that I have described should not be taken as categories that can be fully quantified, measured, or accounted for. Certainly, some parameters can be assessed: for instance, if a score instructs performers to improvise slow, quiet longtones, it might be possible to analyze, map, or calculate relevant aspects of this performance, to interpret what factors led to a particular outcome, and therefore to approximate what improvisation is doing in this case (and how). Nevertheless, the question with contingency is never only what happened or even how it happened in a causal sense; contingency is also concerned with the affect of experience, the color of sound, the preconscious forces that specify an improvisation as of this moment and no other. In other words, it is not strictly the "outcomes" that interest us, but the affect of the interactions themselves-how they feel, how they move, what unspeakable forces traverse the body. As a space in which meaning, signification, emotion, and sound vibrations circulate among and through participants, improvised music performance is a field of affectuation. Music perception-whether because of a state of "flow" or because of the fact that sound vibrations themselves are a form of affect-does not solely reside in conscious experience. ${ }^{13}$ As such, contingency (rather than "chance" or "indeterminacy") points to the fact that music always exceeds our capacities of knowing. There is always an excess of affect that escapes capture, "inseparable from but unassimilable to any particular functionally anchored perspective" (Massumi 35).

In my view, it is through this overflow of affect that contingent experience reveals itself as something that, no matter how causality is traced, defies definitive analysis. As Robin Mackay puts it in a different context:

The ideologies of probability and chance, no less that of divine necessity, hallucinate a universe in which-at least-the parameters within which events may take place can be circumscribed. But an event, a real contingency, is precisely something that overflows this compartmentalization and management. ${ }^{14}(2)$

Even while you are perceiving music, something is exceeding you. Contingency references this excess that is partially outside of all perceptive experience, but is especially present in music, whose vibrations linger in silence. Is not sound, which moves with affective force, also exactly something that overflows us?

\section{Singularity}


Critical Studies in Improvisation / Études critiques en improvisation, Vol. 12, No. 2

Taken together, each of the points raised by contingency leads to another, fourth implication: the collapsing of binary oppositions into a constellation, the interdependence that forms this constellation, and the affect that connects all factors in experience, all lead to the conclusion that improvisation, when considered as a contingent encounter, is always a singularity. ${ }^{15}$ Certainly, scholars have already noted that improvisation is understood differently in different contexts. For example, as Georgina Born, Eric Lewis, and Will Straw write in the introduction to Improvisation and Social Aesthetics:

It is, then, the differences in how the term 'improvisation' may be employed, and the ways in which practices, discourses, and cultures of improvisation diverge or are in tension, that are of greatest interest, since they point to the radically contingent nature of improvisation as it is understood and empractised, and as it has been developed historically in relation to specific artistic media. (11)

What would it mean to take the perspective outlined in this quote further, to more fully consider improvisation in its 'radical contingency'? In my view, it is not only that different genres and cultural practices understand improvisation differently, but also that each improvisation within a given context is radically contingent. Put another way, understanding what improvisation is or is doing involves something different every single time it is enacted. Placing contingency at the center of the inquiry points to the necessity of re-contextualizing, over and over again, what improvisation means in a given context (and how) - not only because it might be understood differently between cinema and music, for example, but also because from the viewpoint of contingency, those generic and historical conventions are only one of the many interacting factors that determine the significance and actualization of improvisation to those practicing it in a singular moment-and because those conventions themselves are contingent. ${ }^{16}$

So much of this hinges on what is meant by the notion of "singularity," and here it is instructive to gloss Deleuze's understanding. While there is no space here to thoroughly address his view, the crucial point is that when I call improvisation a singularity, I do not mean to oppose it to universality. ${ }^{17}$ In the same way that "contingency" here combines both openings and closures, singularity in the Deleuzean sense is not opposed to universality but incorporates it. As Massumi writes:

The singularity of the event is not in contradiction to its generality. The singularity is in necessarily contingent excess over the generality ... The general, necessary conditions define the event as belonging to a recognizable class of events. The singular, contingent ingredients give it its uniqueness, its stubbornness in remaining perceptibly itself in addition to being a member of its class-its quality. The event retains a quality of "thisness," an unreproducible being-only-itself, that stands over and above its objective definition. (222)

There are always general conditions that are reproduced from event to event; but these generalities never exist without singularities as well, no repetition without difference. ${ }^{18}$ To return to Born, Lewis, and Straw, then: media formats, cultural discourses, and specific understandings of improvisation (or anything else) do create contexts that influence what improvisation is/does, and those contexts carry forward in time. But equally, those contexts do not pre-exist as static blocs within which people practice corresponding viewpoints; rather, media formats, cultural discourses, and specific understandings only exist as they become actualized by specific people in specific times, places and situations, as they are enacted in between the relations of subjects/objects/environments. Elements of history and of generic or cultural conventions repeat as they are carried forward, but as Deleuze and Massumi remind us, 
Critical Studies in Improvisation / Études critiques en improvisation, Vol. 12, No. 2

they do not repeat without difference that is productive, difference that is introduced when ideas are performed in specific, contingent situations. ${ }^{19}$

A contingentist perspective is interested in how those differences come about and what they change, a process that occurs in every improvisation. What is radical in this "radical contingency" is only the idea that there does not exist an improvisatory situation that does not correspond to or produce such a singularity, an improvisation that would not be radically incommensurate with every other. As soon as improvisation moves away from a musical/theoretical skill and towards a social encounter, this is a conclusion that must be taken seriously.

\section{Definition}

A sub-argument is threaded through this essay: not only am I proposing that improvisation be understood as a contingent encounter, but I am also arguing that there are real reasons to define improvisation in the first place. This is not the place to fully elaborate the debates that have surfaced about the risks and benefits of defining improvisation. However, it is nevertheless the case that most scholars have taken pains to avoid questions of definition. Indeed, I am tempted to take the same approach here, by offering one interpretation of improvisation that can happily coexist with a plurality of other understandings. But while at first the fact that improvisation always manifests differently would seem to require maintaining its definitional ambiguity, I argue that concretely defining improvisation as a contingent encounter is actually necessary in order to paradoxically guarantee that improvisation is always and first understood as contingent. Furthermore, I believe that not doing so risks obscuring how musical improvisation engages the social.

Understanding improvisation as contingent does not preclude commonalities from being observed across different instances. It only cautions that such commonalities not be assumed or remain more visible than the relevant differences that such commonalities smooth over. Furthermore, there is a danger in neglecting to consider the contingency of improvisation first, since improvisation, when it is invoked, is most often referenced without qualifiers, as a kind of unmarked term. As Ingrid Monson and Scott Currie have argued, treating improvisation in this way tends to allow a host of unchecked assumptions to enter the conversation-assumptions that are typically derived from only one particular way of understanding improvisation, based in what Currie calls "transatlantic improvised music" (Currie). These assumptions often have to do with the political reading of improvisation as a tactic for social justice or the undermining of neoliberal hegemony. But as Currie writes:

Improvisation encompasses a wide range of practices worldwide, and aligning any of these with struggles for social justice depends not on generic formal characteristics of musical processes and products, but rather upon a contingent articulation of culturallyspecific meanings by artists, professionals, and audience members invested in certain compelling narratives that structure musical experience in relation to their own needs for agency and empowerment. (7)

Additionally, as Georgina Born writes in her essay "After Relational Aesthetics," many of the assumptions and quasi-utopian claims made on behalf of improvisation tend to derive from the immediate microsocial scene in which musicians are seen as equally participating in a collective performance. Not only have these arguments overdetermined political readings of improvisation, but they also discount the other ways that music engages myriad social relationships, and the way that music is mediated across what Born calls "planes" of interaction. 
Critical Studies in Improvisation / Études critiques en improvisation, Vol. 12, No. 2

The broad tendency to focus A) on transatlantic improvised contexts, and B) on the microsocial scenes inside these contexts, together strongly implies a specific definition of improvisation without identifying it as such, a "particular masquerading as a universal." Thus, there are real stakes-epistemological and otherwise -in the refusal to define, and to define rigorously, over and again, what improvisation means.

Indeed, I fully agree with Monson, Born, and Currie regarding the necessity of attending to cross-cultural differences. But again, the perspective of contingency pushes the argument further: not only does the significance and meaning of improvisation differ across cultures and media, but also between each instance within the same paradigm or context as it is enmeshed in diverse social relations. Fixing a definition of improvisation with contingency at the center suspends our assumptions about what improvisation is in a given instance, and forces a rigorous re-contextualization in each case. In other words, if improvisation is an empty frame filled in by the particulars of time, place, and situation, it must be defined anew each time it is invoked. And for improvisation to retain its singularity in every single case, it must be concretely understood as an empty or contingent universal, a characterization that would not limit or constrain improvisation's possibilities. That is, if improvisation is a/ways a singularity, then it must have a paradoxical structure that guarantees contingency. Contingency in this view would be the necessary but nevertheless empty foundation of improvisation, upon which the contextspecific details can play out. Defining improvisation in such a way makes only one claim regarding the ontology of improvisation, namely that it is always, inherently, and only contingent. In order to make a case that improvisation is singular even within the same aesthetic world, I will quickly compare two examples of "transatlantic improvised music," asking "what does this music depend on?"-or, put another way, "how is this music contingent?"

\section{Comparison}

In my work, I have been comparing instances of improvisation that I understand to operate within the Western avant-garde context. ${ }^{20}$ Here, I have chosen to excerpt a very brief comparison between a freely improvised track and the seminal recording of Eric Dolphy's “Out to Lunch" in order to show the inadequacy of the "sliding scale" model of improvisation I identified earlier. On this conventional view, what jazz musicians are doing when they play a standard and what they are doing when they freely improvise are variations on the same fundamental activity - a difference in degree rather than kind. In my view, thinking improvisation with contingency complicates such a reading, given its expanded attention to factors outside the scope of music-theoretical concerns.

"Waves, Linens, and White Light" appears on Mr. K's 2015 release Left Exit. On this album the founding members-Karl Hjalmar Nyberg and Andreas Skår Winther (tenor and drums)-are joined by Michael Francis Duch and Klaus Ellerhusen Holm (bass and reeds). Following contingency all the way out involves thinking all of the openings and closures present at a given moment of performance: not only the particular life experiences that have contributed to musical subjectivities, but also the objects and multiple environments present. Additionally, the score (literal or figurative) plays an important role in conditioning activity. What kinds of possibilities does it allow or disallow? How do the musicians themselves approach and manage contingency? Finally, what of the contingencies opened and closed after the performance? What of the improvisations that listeners perform while listening to a recording from 1964 or 2015 in $2018 ?$

"Waves, Linens, and White Light" is a freely improvised track that nevertheless is almost purely repetitive. The bass and tenor saxophone re-articulate note after note, with only slight changes 
throughout. Meanwhile, the drums and clarinet accompany these rolling notes with quiet textural gestures. The whole track consists in this steady fabric of sound, from beginning to end, a small, self-contained world that is disclosed over two minutes and forty-seven seconds. What is improvisation doing here? It is certainly not providing a medium for virtuosic self-expression, nor is it producing unexpected variations; very quickly, the sounds become eminently predictable.

According to a model of relative freedom or relative restriction, this score-less track should be a space of pure or absolute freedom-yet the track sounds to our ears as if it might not be improvised at all.

However, from the perspective of contingency, first of all, the repetition we hear is not repetition at all; rather, through the physicality of the specific instruments - the fact that wind instruments must be blown, the fact that the bass bow is only so long-we hear in each re-articulation the physicality of the notes themselves, which, by virtue of this physicality, are always singular iterations-"just the same, but brand new." ${ }^{21}$ Thus and even still: we know that the presence of repetition is not antithetical to the presence of improvisation, because improvisation has to do in this case not with the open and limitless potential of the music but with the contingent magic, the closed specificity of these musicians selecting these notes, colliding in this context. Yes, the improvised performance is ostensibly open, but it is always only open in a certain way: the performance is conditioned by the musical histories of the participants themselves, and their group aesthetic as it has been developed over a period of years. ${ }^{22}$ The question is not about the openness of the music but the surprise of contingency that occurs when these four musicians set their musical voices against one another.

Following contingency outward from the physical studio space (in itself crucial for the resulting performance ${ }^{23}$ ) leads to the Conservatory at Trondheim, where the members of Mr. K studied (and where the guests on this album teach or have taught). Among the relevant factors here is the pedagogical approach, which differs from the ways improvised music is generally taught in U.S. institutions. Following further out, it becomes clear that this conservatory and its pedagogy both were established with a very specific intent that arose due to a very specific history of jazz and improvised music as it developed in Norway. In other words, the distinctiveness of the pedagogy is not an accident, but a part of a lager historical and historiographical effort to reify Norwegian improvised music as an artistic practice unto itself, rather than a derivative music. ${ }^{24}$ The pedagogical efforts undertaken through the conservatory were in some ways mirrored by historical discourses, the proliferation of jazz festivals, and concerted efforts by governmentfunded Norwegian jazz organizations to contribute to the world stage a specifically Norwegian cultural art form. Each of these factors in turn contribute to the construction of an aesthetic approach to improvised music that is -if not fundamentally different than others - at least discursively prevalent (and therefore influential). Again, my argument here is not that this context pre-determines how Norwegian improvisers will sound. My question is only: given this context, how can we talk about "improvisation" as if it references a uniform set of behaviors? To what extent can we then say that Mr. $\mathrm{K}$ is doing the same thing that I am doing with my friends when we improvise together?

It is the same with "Out to Lunch," a contingent historical document that contains traces of its emergence. As with the 'discursive' environment of Norwegian improvised music, the 'job' of the performers on "Out to Lunch" is conditioned not only by particular musical personalities and/or a collective approach to improvising but also by the generic conventions of bop, including its most basic assumptions (the drummer plays time, the bass walks, the solos come after the head, and so on). In this case, it is also deeply affected by the composition, the mere existence of which affects and conditions musical behavior, no matter how loosely. What is contingent in this performance is both what is fixed or implied by the score (there will be a head-in and a head- 
out, there will be solos in the middle, the drums will keep time, the vibes will comp, etc.) and what this fixity opens up (the interpretation and execution of the head, the solos that are taken, the interactions these solos engender, the limits that Dolphy's ferocious sound pushes the other musicians to question, come up against, or abandon outright). Equally, there is closed contingency in the functionally 'fixed' subjectivities present (all the accidental qualities that add up to form the musician's predilections, tastes, interests, etc. at this particular moment) and there is open contingency in the consequences of various interactions (what happens when they come together to record? What happens when the closed recording opens again into the world, each time we listen?).

To choose only one route of thought, I focus here on the generic conventions that governed jazz performance in 1964. As we know, Out to Lunch! as a whole is a record that starts to re-orient these bop conventions even as they are being performed. We can hear the straining through which Dolphy -along with Tony Williams, Bobby Hutcherson, Richard Davis, and Freddie Hubbard-reaches for new sounds from the inside out. "Out to Lunch" refuses to give way either to complete abstraction or complete coherence, existing in a liminal in-between that allows for all kinds of possibilities. In this context, the very frame of what constitutes 'walking', 'keeping time', or 'comping' is being expanded in real time through the performance, re-orienting the sense of what is musically thinkable.

What does it mean to simultaneously deploy bebop conventions and to subvert them? What does it mean to do so there, then, and for these musicians? In this case what I am emphasizing is the historical moment in which this recording takes place, as well as the musical personalities who have gathered there. The point is not that one of these factors matters more than another; the point is that understanding improvisation is entirely dependent on all of them at once. We see a singular encounter of musicians, instruments, and circumstances, in which the participants simultaneously adhere to the bop tradition and also push it so far that it bends. For Dolphy to do this through his eccentric music, "both rooted and out there, immanent and transcendent" (Moten 26), ${ }^{25}$ is to enact a profoundly political disjuncture whereby noise is recast as music. In Jacques Rancière's terms, the crucial function of improvisation in this moment is the way it redistributes the jazz sensible. ${ }^{26}$ This music produces a rift in the fabric of 'common sense' and straddles that gap by pointing to its distance. As listeners, we are forced to confront this rift, ${ }^{27}$ but we cannot recreate the circumstances under which it first sounded to unprepared ears.

It is point blank impossible to improvise like that anymore. The frame of reference has been broken and expanded and manipulated in all manner of ways since then, and trying to pretend otherwise results only in a pale imitation of what they were doing, or more importantly what they were reaching to do without full comprehension of what that meant. This is an improvisation that is utterly dependent-for its urgency, for its risk, for its sound-on the moment in which it was made. Dolphy - so creatively ambitious, yearning not only for unknown future sounds but also to get the stuff in his head out there, and so backstopped by his professional life as a sidemancomes into his own session with a lot to say and with musicians who want to talk. His solo entrance at 0:44 communicates everything. It all happens in this moment.

There is too much more to say about both of these musical examples. But even through a brief comparison, these cases emphasize the incongruity between one improvisation and the next. This incongruity is not only the result of musical vocabulary, stylistic conventions, or the social histories of the participants; it is also a result of the unquantifiable, preconscious affect that moves between the performers who together create them, tying the situation together. My reliance on the term contingency is as much about this unknowable excess as it is about the 
Critical Studies in Improvisation / Études critiques en improvisation, Vol. 12, No. 2

particular constellation of possibilities and impossibilities that may be present. If paying attention to contingency emphasizes the particularities involved in a performance, it also means thinking the felt but unspeakable affect that connects these particularities through embodied experience. These affects are both impossible to fully know and impossible to recreate. We already intuit so by listening.

\section{Conclusion}

In this essay I have tried to sketch some implications for thinking improvisation as a contingent encounter. At the end of the experiment, a picture forms of improvisation as something decoupled from freedom or novelty - a picture more centered in the kind of contingency that is always already proper to being in the world, and more akin to everyday experience. How does this affect thinking the aesthetics and politics of improvisation? It would mean first of all leaving behind the association between improvisation and variation, innovation, or counter-hegemonic practices. Those characteristics may at any point be operative in a given improvisation, but their operation is exactly what must be explained, rather than assumed.

This experimental definition is promising to me for its potential to open up new avenues of thought at the same time that it may guard against certain definitional assumptions. However, as a last gesture, it is also necessary to address at least one of the risks in this perspective: if all improvisation and indeed all music is contingent, what difference does improvisation make? Does not conflating contingent interaction with improvisation deplete improvisation of its special qualities, rendering it meaningless? This is indeed a risk, for at the end of the day, it does not seem to me that there is a meaningful ontological difference between a saxophonist navigating the parameters of the jazz tradition according to the vocabularies in which they are immersed, and a person on the street navigating their respective parameters by walking home (according to the vocabularies in which they are immersed). However, if we return to the musical examples, we can see one aspect of each performance that does seem to differentiate their contingent interactions from just any experience in the world.

Of all that may be said of the improvisations sketched here, in my view, what distinguishes these musical examples from contingent encounters in everyday life is the shared element of liveness, through which-without claiming some sort of total situational awareness-the musicians nevertheless actively threw themselves into the game of musicking. This is an element of liveness that does not refer only to embodiment in an active situation, since we are already embodied in everyday life; rather, liveness refers to this embodiment as well as an open, aware receptivity, a self-conscious engagement with the contingency of the situation as it unfolds. The musicians in these examples do not know what is going to end up happening, but they are aware of and are intentionally pursuing the contingency and the plurality of those moments. This is a kind of liveness that may or may not be operative as we move through the world, a liveness that attends to the texture of the embodied activity. Thus, if we distinguish "musical" improvisation through liveness, improvisation becomes not a specific kind of behaviour but a potentiality hidden within each moment. "Musical" improvisation, in this sense, is a modality that can be activated by our states of attention.

From this perspective, even brushing one's teeth becomes an unrepeatable act-a singularitybecause the context will be different tomorrow, with different thoughts on your mind, in a different light, perhaps smelling the bread you plan to bake in the morning, where today there is none. Moreover, the tooth-brusher may at any point start to listen to the vibrations of the bristles on their teeth, to reflect on their mood, to focus on the task at hand, doing the very best job that they can cleaning their teeth, or to otherwise attend to their situatedness in the moment. 
Critical Studies in Improvisation / Études critiques en improvisation, Vol. 12, No. 2

Repetition, as we see in the Mr. K example, is both strictly speaking impossible and also beside the point, since any repetitive action can be improvisatory or not; the point is rather about our modes of engagement. ${ }^{28}$ Through the notion of liveness, it is possible for improvisation to remain both the contingent medium of existence as well as a practice that, in all of its banality, still makes a difference.

\section{Notes}

${ }^{1}$ See the introduction in Lewis and Piekut, The Oxford Handbook of Critical Improvisation Studies for a thorough overview.

${ }^{2}$ One example of such a definition is offered in the Improvisation Studies Reader: "a social activity that cannot be readily scripted, predicted, or compelled into orthodoxy" (Heble and Caines 2). (It is important to note that even here, when a definition is offered, Caines and Heble immediately follow it with other, supplementary notions, building a multiplicity of definitions into the definitions themselves.) While not a definition per se, another example of such an understanding is offered by Cecil Foster, who, in a conversation broadcast on the Sound It Out podcast, said, "I don't know how I can ever think of improvisation without thinking at the heart of it that there's a subversive element in it" (Foster qtd. in Elliott).

3 This phrasing is from Stewart, Ordinary Affects.

${ }^{4}$ Indeed, in a later essay, lyer himself gestures at the radicality of his viewpoint by writing, "In other words, I am positing a relationship_or more to the point, an identity, a samenessbetween what we call 'improvisation' and what we call 'experience' (Iyer, "Improvisation, Action Understanding, and Music Cognition" 88). In my view, what accounts for that sameness, and the perspective I aim to elaborate here is to do with the ubiquitous presence of contingency in all areas of our lives, even in the practice of perception itself. I am arguing here that improvisation necessarily happens whenever there is contingency, and furthermore that there is never not contingency.

${ }^{5}$ Quentin Meillassoux takes this classical understanding of contingency as his definition throughout After Finitude.

${ }^{6}$ Each of these terms, in turn, carries a multiplicity of meanings. For example, as Alison James has written of "chance," it "may refer either to an event or to that which determines this event, and to a cause or design that is in fact an absence of cause or design" (James 5).

${ }^{7}$ Many scholars have of course noted the presence of restrictions as necessary to improvisation, but improvisation is nevertheless posed as the opposite of those same restrictions. Although the sliding scale model allows for a degree of nuance, it still defines improvisation by juxtaposing it to the restrictions involved: improvisation is the part of this performance that is open, no matter how much or how little of this openness may be present. As I argue below, we may be able to point to relative zones of determination and indeterminacy; but first of all, the 'pointing to' is influenced by where in the process we prioritize looking (i.e., our perspectives), and second, as Deleuze writes, "the fact that one can pass by degrees from one thing to another does not prevent their being different in kind" (Deleuze 2).

${ }^{8}$ For just one example, see Nicholas Cook, "Scripting Social Interaction: Improvisation, Performance, and Western 'Art' Music." 
${ }^{9}$ Cobussen also draws on Bruno Latour's Actor Network Theory to trace interdependent actants in improvisations. In this sense he echoes some of the points raised by Benjamin Piekut, who has detailed an approach to thinking ANT as it relates to music history (see Piekut).

${ }^{10}$ See for instance Oliveros, “The Difference Between Hearing and Listening."

${ }^{11}$ For the sake of space, I am conflating here everything from discursive precedent to physical space to larger structures such as the economy or patriarchy into the notion of "environments." Additionally, there are musical and sounding environments, such as a score being actively performed or the sonic actualization of that score, each of which condition approaches to sound. The fact that these overlap and all affect the improvisation in question should not imply that these environments are equivalent or have equivalent effects; the point is only that they all matter.

12 For more on this "contingentist" perspective, see Sharma, Interdependence.

${ }^{13}$ I am referring here to Mihály Csikszentmihályi's notion of "flow" as a kind of optimal, quasitrance state of performance in which musicians are so absorbed in what they are doing that afterwards they have no real memory of what happened. For more on the cognitive aspect of this state of performance, see Berkowitz, The Improvising Mind. For more on sound as a form of affect, see Thompson and Biddle, Sound, Music, Affect.

${ }^{14}$ What Mackay refers to here as a "real contingency" has to do with Meillassoux's almost transcendental notion of contingency-an event, for example, like the big bang. But through the notion of affect, which singularizes each and every situation by exceeding that very situation, it is also possible to read any quotidian event as something that overflows our abilities to manage and conceptualize. In this sense, all contingencies are already "real."

${ }^{15}$ Marcel Cobussen has recently argued the same, but from the perspective of emergence. While I clearly agree with him, I am choosing to focus on contingency rather than emergence since emergence can tack too closely to a mechanistic (if dynamic) explanation of what is going on. There is a long history of using scientifically-derived models to explain human behavior, and while emergence is certainly interesting, I am taking this opportunity to prioritize the ineffability of affect. To paraphrase Michel De Certeau, mapping improvisations via complexity theory seems to me a bit like tracing the paths of city walkers onto a map; in both cases, the act of tracing is substituted for the experience itself. (See Certeau, The Practice of Everyday Life 97.) Meanwhile, "Never susceptible to pinning down, affect is that moment of singularity ... where a universe pours in, flows out-an unlimited One-All, universal-Singular" (Seigworth 160). In this sense, affect redirects the conversation away from a focus on outcomes, a focus that, for however it takes into account external actants, reduces music to that which can be represented on paper, a music-theoretical flattening of affect. Instead, what I have in mind in invoking "singularity" vis-à-vis improvisation is akin to Chris Stover's perspective (see note 18 below).

16 This is not to say that they are unstable or inconsistent; it is only to say that they are consistent because of a contingent social history, rather than an inherent quality. Generic conventions too are, in Baraka's terms, a "changing same" (Baraka).

17 In fact, quite the opposite. I am taking for granted here, following Bruno Nettl, that improvisation is a true musical universal; but I also follow George E. Lewis in his assertion that improvisation-when understood along the lines I have tried to outline here-becomes radically omnipresent, not just in music but also in everyday life. In his words, improvisation viewed in 
this way is "as close to universal as contemporary critical method could possibly entertain" (Lewis, "Mobilitas Animi” 108).

18 "Below the universal there are plays of singularities, emissions of singularities" (Deleuze quoted in Peter Borum [for the translation]). Or, as Chris Stover puts it: ". . . the temporally unfolding, performing/performed subject is in dialogue with the historically and textually bounded nature of the musical material, and the acting out of this dialogue is what defines the context of some specific performed utterance. Each performance, in this sense, unfolds as a singularity, a double selection of active and passive syntheses that Deleuze would describe as the becomingactual of the virtual space of the performance" (Stover 6).

19 "The actualization of the virtual . . . always takes place by difference, divergence, or differenciation" (Deleuze 212). "Production, on this Deleuzian view, is an unendingly proliferating distribution of all the myriad absolute singularities. Production is necessarily repetition of difference, the difference of each singularity from everything else" (Surin 29).

${ }^{20}$ Notwithstanding the important differences that we know exist between the Afrological and the Eurological avant-gardes, part of the question-as I understand it-that George Lewis raises in making such a distinction is whether or not these practices actually have more in common than we have been led to believe given the discourses that were summoned to keep them apart (Lewis, "Improvised Music"). Here, I take for granted that we can view these similarities under an accepted, if general, paradigm of avant-garde improvised music. Indeed, all the examples I examine fall under Currie's notion of "transatlantic improvised music."

21 This phrasing is from St. Vincent, Actor.

${ }^{22}$ This is not a Bourdieuian argument. With Rancière, Michel de Certeau, and in a way with Arendt, I emphasize the possibility immanent to small acts for the "absolutely new" to occur, particularly when interacting with others. We are of our conditioning at the same time that we are not confined to it. See de Certeau, The Practice of Everyday Life, Rancière, The Philosopher and His Poor for critiques of Bourdieu, and "action" in Arendt, The Human Condition.

${ }^{23}$ For instance, the studio can have a strong influence on the ability to play the kinds of sustained, contemplative sounds we hear on this record, since the ability to hear and to be heard in an environment of pristine quiet helps such sounds to become musically thinkable in the first place.

${ }^{24}$ See Lewis, "Gittin' to Know Y'all”; Heffley, Northern Sun, Southern Moon; The Return of Jazz; The Sound of the North; and Mercer, "How Norway Funds a Thriving Jazz Scene."

${ }^{25}$ I cite Moten here because Dolphy-no matter how he may have avoided speaking about his music in overtly political terms - is nevertheless (partially) constituted in and through "blackness" considered as "the extended movement of a specific upheaval, an ongoing irruption that arranges every line" (1). Again, there is no room here to delve into Moten's aesthetics and ontology of black performance. Suffice it to say for the moment that insofar as black aesthetic production is a surplus generated in response to/as a result of white domination and appropriation, Dolphy cannot but be implicated in this contingent relation. To talk about what Dolphy did when he improvised, we cannot stop at analyzing his phrasing or syntax. We also have to locate the singularities of these improvisations here and to trace their becomings. Dolphy's approach to improvisation is experimental and eccentric both because it warps bop 
conventions and because, as Moten writes, "The avant-garde is a black thing" and "blackness is an avant-garde thing" (32). Thinking contingency here foregrounds the too-often overlooked fact that improvisation is determined by such extramusical parameters as much as by musical ones; it is social and musical at the same time. This overlap is impossible to dissect because it is what brings improvisation into being in the first place.

${ }^{26}$ See Rancière, The Politics of Aesthetics.

27 "Musical listening transforms our auditory attention just when we decide that the sounds we are hearing are music" (Shank 4).

${ }^{28}$ Fundamentally, improvisation as contingent encounter requires that even being unaware of the fact that we are improvising would not mitigate the fact that we are improvising (as in a "bad" version of "Giant Steps," where no one is listening); but unawareness does mitigate the force, efficacy, effect, or magic of improvisation. Once we become engaged, we activate new potentialities.

\section{Works Cited}

Arendt, Hannah. The Human Condition. The U of Chicago P, 1998.

Baraka, Amiri. "The Changing Same (R\&B and New Black Music)." Black Music, by Baraka, Akashic, 2010, pp. 205-241.

Berkowitz, Aaron. The Improvising Mind: Cognition and Creativity in the Musical Moment. Oxford UP, 2010.

Borgo, David. Sync or Swarm: Improvising Music in a Complex Age. Bloomsbury Academic, 2005.

Born, Georgina. "After Relational Aesthetics: Improvised Music, the Social, and (Re)Theorizing the Aesthetic." Improvisation and Social Aesthetics, edited by Georgina Born, Eric Lewis, and Will Straw, Duke UP, 2017, pp. 33-58.

Born, Georgina, et al. "Introduction: What is Social Aesthetics?" Improvisation and Social Aesthetics, edited by Georgina Born, Eric Lewis, and Will Straw, Duke UP, 2017, pp. 132.

Borum, Peter. "The Notion of 'Singularity' in the Work of Gilles Deleuze." Deleuze Studies, vol. 11 , no. 1, 2017, 95-120.

Certeau, Michel de. The Practice of Everyday Life. Translated by Steven F. Rendall. Berkeley: U of California P, 2011.

Cobussen, Marcel. The Field of Musical Improvisation. Leiden UP, 2017. http://www.oapen.org/search?identifier=637220.

Cook, Nicholas. "Scripting Social Interaction: Improvisation, Performance, and Western 'Art' Music." Improvisation and Social Aesthetics, edited by Georgina Born, Eric Lewis, and Will Straw, Duke UP, 2017, pp. 58-77. 
Currie, Scott. "The Other Side of Here and Now: Cross-Cultural Reflections on the Politics of Improvisation Studies." Critical Studies in Improvisation / Études Critiques En Improvisation, vol. 11, no. 1-2, July 2017, http://dx.doi.org/10.21083/csieci.v11i1-2.3750.

Deleuze, Gilles. Difference and Repetition. Columbia UP, 1995.

DJ Spooky and Vijay lyer. "Improvising Digital Culture." People Get Ready: The Future of Jazz is Now!, edited by Ajay Heble and Rob Wallace, Duke UP, 2013, pp. 225-243.

Elliott, Rachel. “Epistemology Series: What Is Improvisation?” Sound It Out, 9 Jan. 2018, http://sounditoutiicsi.wordP.com/.

Heble, Ajay, and Rebecca Caines, editors. The Improvisation Studies Reader: Spontaneous Acts. Routledge, 2014.

Heffley, Mike. Northern Sun, Southern Moon: Europe's Reinvention of Jazz. Yale UP, 2005.

Hurley, Andrew Wright. The Return of Jazz: Joachim-Ernst Berendt and West German Cultural Change. Berghahn, 2011.

lyer, Vijay. "Embodied Mind, Situated Cognition, and ExPive Microtiming in African-American Music." Music Perception: An Interdisciplinary Journal, vol. 19, 2002, pp. 387-414, https://doi.org/10.1525/mp.2002.19.3.387.

---. "Improvisation, Action Understanding, and Music Cognition with and without Bodies." The Oxford Handbook of Critical Improvisation Studies, Volume 1, edited by George E. Lewis and Benjamin Piekut, Oxford UP, 2016, pp. 74-90.

James, Alison. Constraining Chance: Georges Perec and the Oulipo. Northwestern UP, 2009.

Lewis, George E. "Gittin' to Know Y'all: Improvised Music, Interculturalism and the Racial Imagination." Critical Studies in Improvisation / Études Critiques en Improvisation, vol. 1, no. 1, 2004, http://dx.doi.org/10.21083/csieci.v1i1.6.

---. "Improvised Music after 1950: Afrological and Eurological Perspectives." The Other Side of Nowhere: Jazz, Improvisation, and Communities in Dialogue, edited by Daniel Fischlin and Ajay Heble, Wesleyan UP, 2004, pp. 131-62.

---. "Mobilitas Animi: Improvising Technologies, Intending Chance." Parallax, vol. 13, no. 4, 2007, 108-122.

Lewis, George E., and Benjamin Piekut, editors. The Oxford Handbook of Critical Improvisation Studies, Volume 1. Oxford UP, 2016.

Mackay, Robin. "Introduction: Three Figures of Contingency." The Medium of Contingency. Ridinghouse, 2011, pp. 1-10.

Manning, Erin. The Minor Gesture. Duke UP, 2016.

Massumi, Brian. Parables for the Virtual: Movement, Affect, Sensation. Durham: Duke UP, 2002. 
McMullen, Tracy. "Subject, Object, Improv: John Cage, Pauline Oliveros, and Eastern (Western) Philosophy in Music." Critical Studies in Improvisation / Études critiques en improvisation, vol. 6, no. 2, 2010, http://dx.doi.org/10.21083/csieci.v6i2.851.

Meillassoux, Quentin, and Alain Badiou. After Finitude: An Essay on the Necessity of Contingency. Translated by Ray Brassier, Bloomsbury Academic, 2010.

Mercer, Michelle. "How Norway Funds A Thriving Jazz Scene." NPR. http://www.npr.org/sections/ablogsupreme/2013/03/26/175415645/how-norway-funds-athriving-jazz-scene. Accessed 21 Oct. 2017.

Monson, Ingrid. "From the American Civil Rights Movement to Mali: Reflections on Social Aesthetics and Improvisation." Improvisation and Social Aesthetics, edited by Georgina Born, Eric Lewis, and Will Straw, Duke UP, 2017, pp. 78-90.

Moten, Fred. In the Break: The Aesthetics of the Black Radical Tradition. Minneapolis: U of Minnesota P, 2003.

Nettl, Bruno. "Thoughts on Improvisation: A Comparative Approach." The Musical Quarterly, vol. 60, no. 1, 1974, pp. 1-19, http://www.jstor.org/stable/741663.

Nesbitt, Nic. "Critique and Clinique: From Sounding Bodies to the Musical Event." Sounding the Virtual: Gilles Deleuze and the Theory and Philosophy of Music, edited by Brian Hulse and Nick Nesbitt, Ashgate, 2010, 159-180.

Oliveros, Pauline. "The Difference Between Hearing and Listening." YouTube, uploaded by TEDx Talks, 12 Nov. 2015, https://youtu.be/ QHfOuRrJB8.

Piekut, Benjamin. "Actor Network Theory in Music History: Clarifications and Critiques." Twentieth-Century Music, vol. 11, no. 2, pp. 191-215.

Rancière, Jacques. The Politics of Aesthetics. Translated by Gabriel Rockhill, Bloomsbury Academic, 2013.

---. The Philosopher and His Poor. Edited by Andrew Parker, translated by Corinne Oster and John Drury, Duke UP, 2004.

Seigworth, Gregory J. "From Affection to Soul." Gilles Deleuze: Key Concepts, edited by Charles J. Stivale, Acumen, 2005, pp. 181-191.

Shank, Barry. The Political Force of Musical Beauty. Duke UP, 2014.

Sharma, Kriti. Interdependence: Biology and Beyond. Fordham UP, 2015.

St. Vincent. "Just the Same but Brand New." Actor, 4AD, 2009.

Stewart, Kathleen. Ordinary Affects. Duke UP, 2007.

Stover, Chris. "Affect and Improvising Bodies." Perspectives of New Music 55, no. 2 (2017), pp. 5-66, http://www.jstor.org/stable/10.7757/persnewmusi.55.2.0005.

Surin, Kenneth. "Force." Gilles Deleuze: Key Concepts, edited by Charles J. Stivale, Acumen, 
Critical Studies in Improvisation / Études critiques en improvisation, Vol. 12, No. 2

2005, pp. 21-32.

Thompson, Marie, and lan Biddle, eds. Sound, Music, Affect: Theorizing Sonic Experience. Bloomsbury Academic, 2013.

Vitali, Luca. The Sound of the North: The Norwegian Jazz Scene. Mimesis International, 2016. 